
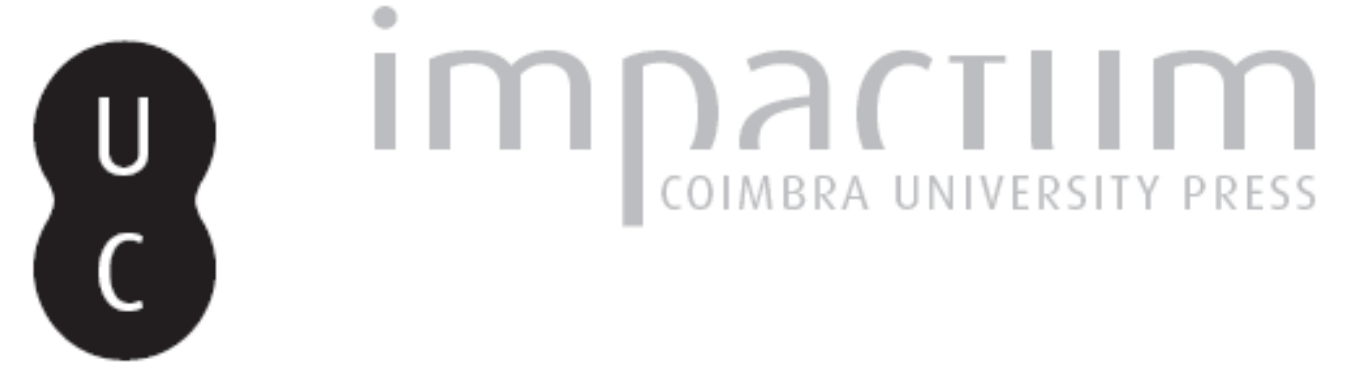

\title{
[Recensão a] NETO, Sérgio - Colónia Mártir, Colónia Modelo: Cabo Verde no pensamento ultramarino português (1925-1965)
}

\author{
Autor(es): $\quad$ Barros, Victor \\ Publicado por: Imprensa da Universidade de Coimbra \\ URL \\ persistente: \\ URI:http://hdl.handle.net/10316.2/36755 \\ DOI: \\ DOI:http://dx.doi.org/10.14195/1647-8622_11_28 \\ Accessed : $\quad$ 26-Apr-2023 11:46:40
}

A navegação consulta e descarregamento dos títulos inseridos nas Bibliotecas Digitais UC Digitalis, UC Pombalina e UC Impactum, pressupõem a aceitação plena e sem reservas dos Termos e Condições de Uso destas Bibliotecas Digitais, disponíveis em https://digitalis.uc.pt/pt-pt/termos.

Conforme exposto nos referidos Termos e Condições de Uso, o descarregamento de títulos de acesso restrito requer uma licença válida de autorização devendo o utilizador aceder ao(s) documento(s) a partir de um endereço de IP da instituição detentora da supramencionada licença.

Ao utilizador é apenas permitido o descarregamento para uso pessoal, pelo que o emprego do(s) título(s) descarregado(s) para outro fim, designadamente comercial, carece de autorização do respetivo autor ou editor da obra.

Na medida em que todas as obras da UC Digitalis se encontram protegidas pelo Código do Direito de Autor e Direitos Conexos e demais legislação aplicável, toda a cópia, parcial ou total, deste documento, nos casos em que é legalmente admitida, deverá conter ou fazer-se acompanhar por este aviso.

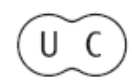


fazer história contemporânea

ESTUDOSDOSÉCULO

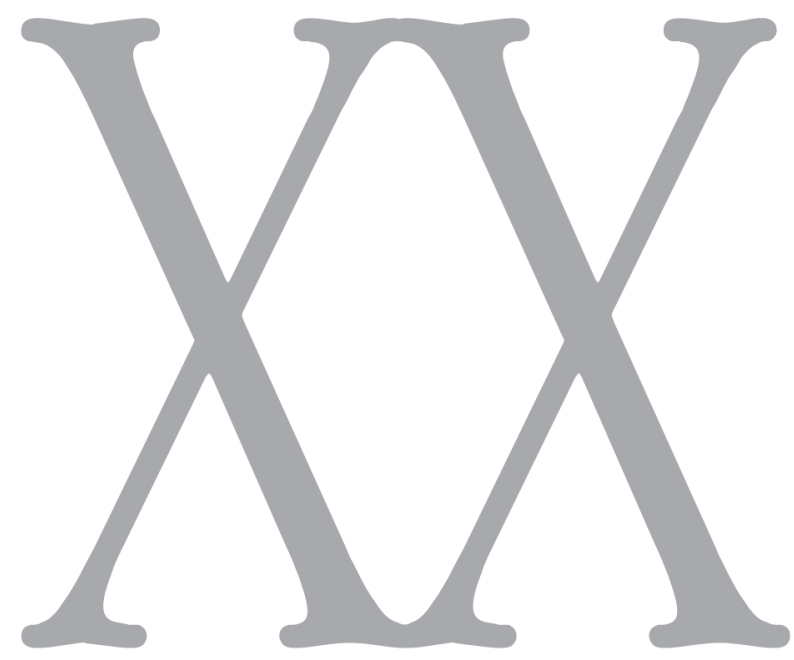

número 11 • 2011

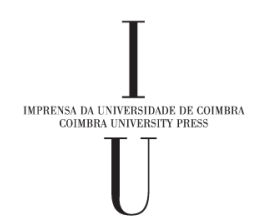


NETO, Sérgio - Colónia Mártir, Colónia Modelo: Cabo Verde no pensamento ultramarino português (1925-1965). Coimbra: Imprensa da Universidade de Coimbra, 2009. 223 p. ISBN: 978-989-8074-85-0.

Inquérito analítico centrado sobre as fontes de propaganda colonial do Estado Novo. Do trabalho heurístico e de análise das diferentes fontes, sobretudo dos periódicos de "vocação" colonial dados à estampa durante o período áureo do Estado Novo, o autor diagnostica os fundamentos e os discursos que nortearam o pensamento ultramarino português em torno da construção da imagem do Cabo Verde colonial. O trabalho heurístico acompanha a explicitação de algumas mitificaçóes e representaçóes que a própria propaganda colonial do regime se encarregou de forjar sobre o Cabo Verde dentro do arco cronológico proposto pelo estudo (1925-1965). Fontes de carácter propagandísticas, e que não escondiam as suas pretensóes discursivas de fazer valer e revelar Cabo Verde junto dos meios e dos sectores coloniais metropolitanos. Visôes metropolitanas sobre o mundo colonial. Mas também visóes coloniais elaboradas a partir da interiorização de escalas e de noçóes metropolitanas. Um facto importante para não deixarmos de pensar o colonialismo como sistema e como doutrina que articula as relaçóes de poder e de dominação, com a invençáo de representaçóes e imagens sobre as colónias e sobre os próprios sujeitos que ele abarca, implica e submete. Por isso, não restam dúvidas que, da propaganda, as colónias e os colonizados emergem como uma invenção da metrópole e dos dispositivos (vários e múltiplos) que o próprio colonialismo póe ao serviço da sua legitimação política e do cumprimento da ambição última das funcionalidades (também várias e múltiplas) que ele pretende instituir e instaurar nas colónias e na metrópole.

Dois elementos centrais trespassam toda linha analítica das temáticas desenvolvidas ao longo deste livro: o colonialismo e a propaganda do Estado Novo. Em síntese podíamos resumir no seguinte: a propaganda posta ao serviço do colonialismo estado-novista, mais precisamente, em torno da então colónia de Cabo Verde. O livro, resultado de uma investigação apresentada inicialmente como dissertação de mestrado em História Contemporânea na Faculdade de Letras da Universidade de Coimbra, foi publicado pela Imprensa da Universidade de Coimbra ${ }^{1}$.

Do colonialismo fica patente a sublimação da imagem de Portugal como potência imperial (com história), e da excepcionalidade da sua política colonial. Facto validado também pelo discurso colonial sobre a imagem de Cabo Verde, então considerado como uma das provas de excelência do colonialismo português, "sentinela do portuguesismo em África", espécie de prolongamento, em certa medida, tropical e insular do Portugal metropolitano.

O livro encontra-se estruturado em quatro capítulos. O primeiro debruça sobre a relação entre a propaganda, o colonialismo e a antropologia, dando

\footnotetext{
${ }^{1}$ Publicado na colecção História Contemporânea dirigida pela Professora Doutora Maria Manuela Tavares Ribeiro. Este livro é o segundo de uma colecção inaugurada com a publicação da obra Estados Novos, Estado Novo, 2 Vol. (2009), de Luís Reis Torgal, a que se segue várias outras obras, de entre elas Campos de Concentração em Cabo Verde: As Ilhas Como Espaços de Deportação e de Prisão no Estado Novo (2009), de Víctor Barros; Portugal e Itália. Relaçooes Diplomáticas: 1943-1974 (2010), de Vera de Matos; e, Museus Para o Povo Português (2010), da autoria de Joana Damasceno.
} 
conta dos processos discursivos coloniais e eurocêntricos sobre as modalidades de representação discursiva do Outro não europeu, através de ideias forjadas em articulação com o pensamento eurocêntrico, racista e racialista, tributário das concepçôes pseudo-científicas da época. Não menos importante é também a articulação desse pensamento eurocêntrico e colonial com as visôes sobre os africanos e outras populaçôes colonizadas, numa ambição clara de tentar a homologar a representação dessas populaçóes com as imagens e os discursos forjados sobre as mesmas. Uma perspectiva que também náo deixou de considerar a forma como a propaganda colonial portuguesa acentuava as nuances das suas especificidades coloniais em África (nos tempos da mística imperial), assim como as complexas relaçóes que se estabeleceram com os postulados luso-tropicalistas de Gilberto Freyre. Este constitui um debate que, em certa medida, o autor retoma com frequência para aprofundar, contextualizar ou complementar determinadas linhas de análise sobre a relação entre a imagem colonial de Cabo Verde, a mestiçagem, e os usos políticos e coloniais do luso-tropicalismo tanto em Cabo Verde (durante o Estado Novo), como também na metrópole e a sua posterior transplantação hermenêutica e ideológica na legitimação do colonialismo português em Âfrica (pp. 25-71).

A inserção de Cabo Verde e as suas relaçôes com o espaço atlântico, africano e europeu enformam a linha analítica do segundo capítulo do presente livro. Contextos que explicam a historicidade do arquipélago, sem perder de vista as acçóes discursivas do intelectuais nativos, os "filhos da terra", que pleitearam a favor dos interesses da colónia e a favor de reivindicaçóes em relação a uma maior participação dos mesmos na governação das ilhas. Tudo articulado com a importância que a problemática da educação ganhou no arquipélago, patente na formação de uma elite letrada que, através dos periódicos da época manifestaram as suas posiçôes bipartidas mas compatíveis, com a pertença a colónia e a fidelidade à pátria lusa metropolitana (pp. 85-88). Tudo resumido nas enunciaçóes expressas num dos periódicos da época: "negros ou brancos, portugueses somos". "Os continentais não são nossos donos, mas sim, nossos iguais" (p. 86). O nativismo (da geração dos intelectuais da segunda metade do século XIX e as primeiras décadas do século XX) e o regionalismo (forjada a partir da década de 1930) não se revelaram de todo incompatíveis e fracturantes com as escalas de pertença ao império ou à nação lusa. Muito embora, muitos dos elementos etnográficos, culturais e antropológicos recenseados pelos trabalhos da época acabariam por ser aproveitados, posteriormente, para a constituição das versôes sobre a identidade e sobre o nacionalismo cabo-verdiano. Contudo, numa dimensão mais crítica, devemos sempre reconhecer os limites entre o recenseamento de determinados elementos culturais etnográficos e as escalas da sua identificação, como elementos cabo-verdianos, mas sempre tributários dos sentidos regionais que se pretendia dar à pertença e à imagem do Cabo Verde atlântico e insular. Por isso, fica sempre o inquérito: o regionalismo é forjado por referência a que quadro geográfico? O regional é sempre parte de um todo. Sendo assim: pretendia-se defender o regionalismo em relação a que escala geográfica? Perspectiva sempre discutível quando tomamos em conta a afirmação de um dos maiores expoentes do regionalismo claridoso, Baltasar Lopes: se o regionalismo representava uma "condiçáo de unidade e de ordem para o nosso núcleo 
particular e uma exigência dos interesses superiores da Nação", porém o mesmo não se coibia em declarar: "sejamos, pois, intransigentemente regionalistas e seremos inteligentemente portugueses" (p. 91). Por isso, deve-se ter sempre em atenção a problemática do regionalismo claridoso e os intentos da sua classificação imediata como manifestação nacionalista e anticolonial $^{2}$. Se hoje é indiscutível a posição marcadamente anticolonial de alguns elementos da geração nacionalista que sucedeu à geração regionalista claridosa, porém continuam a ser sempre discutíveis (na historiografia cabo-verdiana) os limites sobre a posiçấo de alguns actores desta última geração (a claridosa), relativamente aos sentidos nacionalistas das suas acçóes e actuaçôes perante o contexto colonial. Todavia, não podemos perder de vista que, por vezes, muitas das críticas enunciadas apoiam sobre perspectivas postadas e formuladas a partir de demandas contemporâneas exigidas a actores de outras épocas, sem nenhuma contextualização histórica. Porém, neste segundo capítulo da obra, o autor não deixa de recensear as várias posições e perspectivas críticas dadas a público sobre a passividade ou a não combatividade colonial da geração da revista Claridade (pp. 93-98). Debate que acompanha sempre a discussão sobre a problemática da maior ou menor presença ou persistência de elementos de matriz cultural europeia ou africana na sociedade e na cultura do arquipélago. Um debate

\footnotetext{
${ }^{2}$ Veja-se a este propósito: BARROS, Víctor - "As «sombras" da Claridade: entre o discurso de integração regional e a retórica nacionalista". In: TORGAl, L. R.; PIMENTA, F.; SOUSA, J. (Coord.) - Comunidades Imaginadas: Nação e Nacionalismos em África. Coimbra: Imprensa da Universidade de Coimbra, 2008. ISBN: 978-989-8074-57-7. p. 193-217.
}

que conheceu o seu ponto máximo com o discurso e a perspectiva de Gilberto Freyre sobre o arquipélago e o contra-discurso de Baltasar Lopes, assim como as reacçóes de outros intelectuais que tinham visto as suas expectativas defraudadas pelas posições do sociólogo brasileiro sobre a maior predominância do elemento africano em detrimento da herança lusa na cultura e na sociedade do arquipélago (pp. 98-111). Pois, não teria sido a Claridade, em certa medida, um modelo para a propaganda colonial? Aliás, tal como sugere o autor, a produçáo literária dos claridosos, ao ter tocado nos problemas fundamentais do arquipélago, não deixava de ser equiparada como exemplo de empenho cívico, compatível também, em certa medida, com o âmbito colonial e discursivo do próprio regime (p. 165).

A imagética do "cabo seco" é produzida a partir dos periódicos coloniais ainda dos tempos da República. A ideia de "cabo seco" é construída a partir das memórias das estiagens que provocavam as crises alimentícias no arquipélago. Imagem que não deixou também de ser acompanhada pelas ambivalências sobre a ideia de um população "pacífica" e "indolente", mas que, em certa medida, apresentava "alguns effeitos apreciáveis de civilisação” (pp 116 e 118). É neste terceiro capítulo que o autor explicita a transição da imagem de Cabo Verde, de "colónia mártir" para "colónia modelo", principalmente a partir dos meados da década de 1920 (p. 120), identificando os principais autores das ideias que alimentaram a construção da imagem colonial contemporânea do arquipélago. Autores como Osório de Oliveira, Augusto Casimiro ou, ainda, Julião Quintinha, constituem os principais mentores das imagéticas forjadas sobre o arquipélago, desde a ideia de Cabo Verde como "sentinela do portuguesismo" ou 
“pequeníssimo Brasil” (p. 127), passando pela do "Brasil miniatural" e "pequeno Portugal desterrado” (p. 133), até o “arquipélago da melancolia” (p. 135). Perspectivas também entrecortadas por visóes "desencantadas" de outros autores, como Abel Botelho, que considerou o arquipélago como o "anfiteatro de maldição e de treva” (p.136). Segundo Sérgio Neto, a imagética modelar instala-se entre os finais da década de 1920 e os inícios da de 1930 a partir da panóplia de periódicos que surgiram nesta altura e postos ao serviço da propaganda colónia do regime salazarista, assim como a participação ou colaboração "assídua" de escritores cabo-verdianos que iriam ajudar na fixação, se não mesmo na "cristalizaçáo" da imagem do arquipélago como "paradigma da colonizaçáo lusa" (p. 141 e segs.). A imagem de colónia modelo foi embalsamada pelo discursos da sublimação da imagem da "riqueza cultural" do arquipélago, romanizando e, em certa medida, escamoteando e compensando a realidade das suas dificuldades locais (p. 143). Portanto, devemos admitir que a construção da imagem colonial contemporânea de Cabo Verde não constitui uma obra exclusiva de autores metropolitanos, mas sim um processo no qual também participaram e corroboraram algumas visôes complementares forjadas a partir do arquipélago e por autores do arquipélago. Porém, com influências cada vez mais marcantes do luso-tropicalismo, as imagens sobre Cabo Verde passaram a ser cada vez mais tributárias das visóes sobre a propensão supostamente mais africana ou mais europeia do cabo-verdiano. Concepçóes binárias que, por vezes remetiam as representaçóes dos cabo-verdianos para as margens da sua condição de africano indolente, infantil, inconsequente, mas também reconheciam, por vezes, no ilhéu as qualidades de inteli- gência de um "assimilado", um "subalterno do colonizador", "auxiliares preciosos na valorização do nosso vasto império africano" (pp. 160-161). Bálsamos retóricos como o luso-tropicalismo e a sublimação discursiva sobre a fecundidade cultural do arquipélago (único em todo o então conjunto ultramarino), acompanharam a reificação de uma imagem idílica de Cabo Verde, mas também satisfaziam os intentos propagandísticos salazaristas, na década de 1950 , em torno do mito do Portugal indivisível e múltiplo de Minho a Timor. Contudo, o dualismo binário África/Europa trespassava sempre todas as perspectivas forjadas, sempre num jogo discursivo de acentuar a dimensão civilizada do cabo-verdiano por oposição ao africano continental; estratégia que visava fundamentalmente, apartar Cabo Verde do referencial africano estereotipado, mesmo quando se recorriam a autores e especialistas estrangeiros para estudarem determinados aspectos do arquipélago e emitir parecer sobre o mesmo (pp. 169-170). Em jeito de ressalva, importa referir um pequeno lapso presente no livro relativamente ao aparecimento $\mathrm{da}$ obra Aventura e Rotina de Gilberto Freyre, e que Sérgio Neto indica entre parêntese o ano de 1933 (p. 155), quando eventualmente pretendia referir à obra-mestra do sociólogo brasileiro, Casa Grande e Senzala, que teria surgido precisamente nesse ano (1933). Aventura e Rotina só foi publicada nos inícios da década 1950, mais precisamente, em 1953, depois das viagens que o sociólogo brasileiro empreendeu às terras do então ultramar português, a convite do regime salazarista.

A última parte do livro poder ser reduzida na expressão da primeira frase que abre o capítulo: "O que quer que tenha aproximado portugueses e cabo-verdianos deve ser procurado na quase obsessão 
que ambos acalentaram em (re)definir a sua essência ou "espírito de um povo" (volksgeist)" (p. 177). Buscas e obsessōes mediadas pelo processo de identificação de alguns elementos tidos como transversais à "alma" dos dois povos: de entre eles, a presença constante do mar, e o destino sempre errante, enquanto povos migratórios. Embora com as suas especificidades moldadas pela geografia e pelo processo histórico, as imagens coloniais do arquipélago eram sempre tributárias de um olhar postado a partir das escalas metropolitanas: mesmo quando a originalidade do arquipélago era sublinhado, náo podemos perder de vista a dualidade que sempre trespassou e que, por vezes ainda hoje caracteriza certos discursos contemporâneos sobre a representação de Cabo Verde. Facto para salientar que o dilema da propaganda colonial deixou os seus resíduos na forma como ainda hoje, por vezes, é postada a discussão sobre Cabo Verde ou sobre o cabo-verdiano: europeu em África? Africano europeizado? Ou nem europeu nem africano? (p. 204). Em síntese, a valência desta obra não reside no estabelecimento e na fixação de respostas definitivas sobre essas questóes, mas sim na análise das fontes, dos contextos e dos discursos coloniais que determinaram os sentidos dessas formulações sobre a representação do arquipélago e das suas populaçôes. Um exercício hitoriográfico importante que o autor dedica na contextualização das historicidades da formação dos discursos e das representaçóes das identidades, em contexto de dominação colonial, de forma a podermos lidar e problematizar criticamente a nossa condição histórica pós-colonial.

Victor Barros

Bolseiro de doutoramento da Fundação Calouste Gulbenkian/CEIS20
GUMBRECHT, Hans Ulrich - Lento presente. Sintomatologia del nuevo tiempo histórico. Madrid: Esco1ar y Mayo, 2010. 181 p. ISBN 978-84-937906-0-8.

Autor de firmada obra e pensamento, Hans Ulrich Gumbrecht tem tido em Portugal uma recepçáo restrita aos estudos literários, especialmente entre os seus teóricos, aspecto que se evidencia pela falta de obras traduzidas no nosso país.

Nascido na Alemanha em pleno fim da II Guerra Mundial, Gumbrecht tem contribuído com o seu pensamento no campo da filosofia, teoria literária, teoria dos media ou história cultural, podendo falar-se de uma espécie de programa intelectual perseguido por Gumbrecht.

Lento Presente - Sintomatologia del nuevo tiempo histórico é uma obra composta por um conjunto de textos dispersamente publicados pelo autor, ao longo da última década. Inicia-se com um interessante prólogo que se lê como uma narrativa, em que José Luis Villacańas - Professor catedrático, filósofo político, historiador e teórico das ideias e das mentalidades da Universidad Complutense de Madrid - diz que "ler Gumbrecht é um sopro de ar fresco".

E de facto, é. A escrita de Gumbrecht lê-se como um romance, sem deixar, no entanto, de nos colocar alerta para questóes centrais: serve o passado como experiência?; permite-nos criar uma imagem do futuro?; podemos ainda aprender com o passado?; e o que pode ser feito com o nosso crescente conhecimento sobre esse passado?; estará esse passado destinado a tornar-se normativo para o presente?

Essas questôes inscrevem-se no mais amplo debate sobre a aceleração e desaceleração do tempo histórico que se dilata e que se estende oferecendo distintas e dificilmente conciliáveis perspectivas aos 